\section{Atypical presentation of Gilles de la Tourette syndrome}

SIR: The association between Gilles de la Tourette syndrome (GTS) and some psychopathological conditions (mainly depression, aggression and obsessivecompulsive behaviour) has been demonstrated (Towbing, 1988; Trimble, 1989; Robertson, 1989). However, whether these are an integral part of the syndrome or secondary to it remains to be proved (Robertson, 1989). In the case of obsessivecompulsive disorder (OCD), it is becoming increasingly evident that there is a strong association between GTS and obsessional thought and behaviour in GTS patients and in their family members as well (Kurlan et al, 1986; Pauls et al, 1986). We now report a patient who can contribute to a better understanding of this hypothesis.

Case report. A 75-year-old man developed the classical picture of GTS at the age of 72. His family history is not complete since he never knew his parents. He has four daughters and two sons. One of his daughters presents an altered behaviour with obsessive ideas and compulsive acts (she must bend forward three times before passing through a door), but she does not suffer from tics. The patient himself (and this is asserted by his wife) had no tics until age 72 , except possibly exaggerated blinking. He had, however, shown an altered behaviour since childhood, with obsessive ideas about religion and death and a compulsive need to touch any crystal object set upon a table a given number of times. At the age of 72 he received distressing news, and started having dystonic motor tics involving face, neck and shoulder, sensory ticks affecting the pharynx and vocal tics with sound emission, throat clearing, grunting, and verbal outbursts. There have been fluctations and slight changes in the type of tics, but since their onset he has not suffered from OCD. All tests to rule out secondary tourettism were negative, except magnetic resonance imaging, which showed small hyperintense $T_{2}$ weighted images in the subcortical white matter, probably of vascular origin. The patient was treated with clonazepam, tetrabenazine, clonidine, pimozide, fluoxetine and imipramine with no improvement. With haloperidol at low irregular doses the tics are kept under control.

This patient developed the clinical picture of GTS at age 72 . For 60 years he had only presented OCD consisting of obsessive ideas and compulsive behaviour. Although the touching of objects is considered by some to be a motor complex tic (Trimble, 1989; Robertson, 1989), this patient had made a ritualistic ceremony out of it, representing, in our opinion, a compulsive act. It is widely accepted that GTS is an inherited autosomal dominant disease (Kurlan et al, 1986; Pauls et al, 1986) with very heterogeneous symptoms. We believe that this case supports the hypothesis that GTS and OCD are both transmitted by a single gene. Also, the expression of this gene may be different in the same patient in the course of his life. Probably the case referred to by Robertson (1989) as having a Tourette-like syndrome but with OCD from the age of 10 is similar to ours, we suggest that many patients in whom GTS symptoms begins during adulthood may have suffered from OCD for years but that this behavioural problem was not recognised.

Kurlan, R, Behr, J. Medved, L., et al (1986) Familial Tourette's syndrome: report of a large pedigree and potential for linkage analysis. Neurology, 36, 772-776.

PAULS, D. L. \& LECKMAN, J. F. (1986) The inheritance of Gilles de la Tourette's syndrome and associated behaviours. Evidence for autosomal dominant transmission. New England Journal of Medicine, 315, 993-997.

Robertson, M. M. (1989) The Gilles de la Tourette syndrome: the current status. British Journal of Psychiatry, 154, 147-169.

TowbING, K. E. (1988) Obsessive-compulsive symptoms in Tourette's syndrome. In Tourette Syndrome and Tic Disorders: Clinical Understanding and Treatment (eds D. J. Cohen, R. D. Braun \& J. F. Leckman), pp. 137-151. New York: J. Wiley and Sons.

TRIMBLE, M. R. (1989) Psychopathology and movement disorders: a new perspective on Gilles de la Tourette syndrome. Journal of Neurology, Neurosurgery and Psychiatry (Special suppl.) 90-95.

\author{
G. LinAZASORO \\ B. Olasagasti
}

S. Neurology

J. F. Marti Masso

Hospital Aránzazu

San Sebastián

Spain

\section{Delusion of jealousy}

SIR: Soyka et al, in their study on delusional jealousy (Journal, April 1991, 158, 549-553) concluded that gender is an important factor in the development of a delusion of jealousy among patients with alcohol psychosis and those with schizophrenia. They used the $\chi^{2}$ test, and reported that the difference in the prevalence of this symptom between the sexes was statistically significant $(P<0.01)$ in these two groups.

Regrettably, we would like to point out their oversight in the statistical computations. Firstly, the $\chi^{2}$ test is inappropriately used for the group with alcohol psychosis as one category has a frequency of less than five. There was only one female patient with delusion of jealousy. Fisher's exact test would have been the appropriate choice.

Secondly, while the $\chi^{2}$ test was used appropriately in the schizophrenic group, the computed result was incorrect. Using their published data (16 out of 864 male patients and 36 out of 1220 female patients had delusional jealousy), we found that $\chi^{2}$ was 2.53 and $P$ was greater than 0.05 at 1 d.f. Using Fisher's exact 
test, $P=0.059$. These results show that the observed difference in the prevalence rate was not statistically significant. Therefore the authors may not conclude that gender is important in the development of delusional jealousy in schizophrenia.

St Mary Abbots Hospital

S. H. ONG

Marloes Road

London W8 $5 L Q$

\section{A HUNDRED YEARS AGO}

\section{The feeble-minded}

There is a widespread class of people from whom personal sympathy is seldom withheld, but to whom, from restrictions in one way or another, the tangible charity of boards of guardians and other authorities cannot be extended. This is the class of persons who, in the technical sense of the term, are "feebleminded." Investigations made on children in Board schools, the results of which are to form the subject of the Milroy lectures to be delivered in the course of this month at the Royal College of Physicians, and abstracts of which will appear in the columns of The Lancet, have shown that the number of children comprised in this group is much larger than was formerly supposed. But no powers exist whereby boards of guardians can place them in suitable institutions. A deputation introduced by $\mathrm{Dr}$. Farquharson waited upon Mr Ritchie on Feb. 29th to point this out to him, and to ask his assistance on behalf of these poor creatures, who are from natural defects unable to maintain themselves by honest labour. Mr Ritchie is always sympathetic in such cases, and the deputation was assured that their requisition was one of "no complication", but simply implied a small extension of the powers already existing with regard to the deaf, dumb, and blind. Personally, Mr Ritchie has a strong leaning in the direction of rendering whatever assistance he legitimately can to the object which the deputation had in view, and their proposals will no doubt be very carefully considered. Of course there are questions which require thought; for instance, whether it is the best thing for the feeble minded to be grouped together without association with others of strong minds, and, if not, the proposal of some alternative plan. No douby these and similar points will be judiciously considered by Mr Ritchie and his advisers, and we feel assured that in any event the objects of the deputation will be to a large extent realised.

$$
\text { Reforence }
$$

Lancet, 5 March 1892, 542.

Researched by Henry Rollin, Emeritus Consultant Psychiatrist, Horton Hospital, Epsom, Surrey. 